\title{
The Incidence of Post-Septoplasty Complications Among Patients with Deviated Nasal Septum in Relation to Gender and Age
}

\author{
Abdulwahid S ALQahtani ${ }^{*}$, Shaqra M Shabi ${ }^{2}$, Assaf A Alkatheri ${ }^{3}$, Ahmad A Etwadi ${ }^{4}$, Khalid A Al-Qahtani ${ }^{5}$, \\ Montasir Junaid ${ }^{6}$ and Sadaf Qadeer Ahmed ${ }^{7}$ \\ 1,6Department of ORL-HNS, Armed Forces Hospital, Khamis Mushait, Saudi Arabia \\ ${ }^{2}$ Department of ORL-HNS, Jazan University, Saudi Arabia \\ ${ }^{3}$ Department of ORL-HNS, Aseer General Hospital, Saudi Arabia \\ 4,5 Department of ORL-HNS, General Hospital of Khamis Mushait, Saudi Arabia \\ ${ }^{7}$ Department of ORL-HNS, Sir Syed College of Medical Sciences for Girls, Pakistan
}

*Corresponding author: Abdulwahid S Al Qahtani, Department of ORL-HNS, Armed

Forces Hospital, Khamis Mushait, Saudi Arabia.

Received Date: September 17, 2020

Published Date: November 02, 2020

\begin{abstract}
Background: A deviated septum can present at birth, becomes curved during growth, or can be traumatic due to nasal and facial injury. A deviated septum is usually asymptomatic, but sometimes may be present with difficulty breathing through the nose, nasal congestion, sinus infections, nosebleeds, sleep problems, headache, or postnasal drip. Many methods and guidelines have been scheduled to treat and manage acute nasal trauma; however, re-establishment of anatomical deformities and function is still a challenge. Septoplasty is the required surgical intervention for patients to relieve their nasal obstruction.

Aim: To detect the incidence of post-septoplasty complications and their relationship with patients' age and gender among cases with nasal septum deviation.

Methodology: A retrospective Electronic record-based study was conducted. This study included patients diagnosed clinically with a deviated nasal septum (DNS) and have undergone surgical intervention (Septoplasty) at Khamis Mushait General Hospital. Data extracted included patients' demographics and postoperative recorded complications.

Results: The study included a total sample of 93 patients. Nasal obstruction was the commonest symptom among patients. As for postoperative complications, nasal obstruction represents nearly one-third of the cases followed by external nasal deformity, and smell disturbance.

Conclusion: In conclusion, our study revealed that the only significant post-operative complication incidence in relation with both gender and age groups is a nasal deformity. Nasal obstruction is the most common postoperative complications recorded in general and among male and female patients as well as in all age groups although there is no significant relation to both gender and age groups. Large-scale researches should be conducted to give more understanding and further explanation.
\end{abstract}

Keywords: Nasal septum deviation; Deviated septum; Surgical intervention; Complications; age; Gender

Abbreviations: DNS: Deviated nasal septum; CSF: Cerebrospinal fluid

\section{Background}

The thin wall between the nostrils is made of cartilage and bone and is called the nasal septum. When this cartilage or bone

is off-center (deviated to one side) or crooked, it is referred to as a deviated septum (DNS) [1]. A deviated septum may present at 
birth, curve during growth, or maybe traumatic caused by injury to the nose and face later in life [2]. A deviated septum mostly is asymptomatic, but sometimes may present with difficulty breathing through the nose, nasal congestion, sinus infections, nosebleeds, sleep problems, headache, or postnasal drip [3,4]. Some symptoms of a deviated septum may be treated with medications, but more severe cases of a deviated septum may require corrective surgery $[4,5]$. Nasal septum surgery is one of the most frequent surgical interventions that is performed by Otorhinolaryngologists [6]. DNS was reported in approximately $30-43 \%$ of the population, without nasal obstruction unrelated to gender [7]. However, among patients complaining of nasal obstruction, only $22-30 \%$ have DNS [8]. Septoplasty is the main surgical intervention for patients with a deviated nasal septum to relieve nasal obstruction [9].

In some cases, additional turbinate surgery is performed. Most studies concerned with postoperative improvement reported that about $60 \%$ of patients undergoing septoplasty showed an improvement in nasal breathing [10-13]. Cosmetic complications such as facial swelling or discoloration are unusual with simple septoplasty unless there are unusual complications. Packing is rarely required with modern surgical techniques, although internal nasal splinting for a few days is common. One percent of patients can experience excessive bleeding afterwards, the risk period lasts up to two weeks [14]. Septal perforation and septal hematoma are associated with smell disturbance [15]. Temporary hypoesthesia of the upper incisor teeth after surgery is not rare [16]. The numbness

\section{Results}

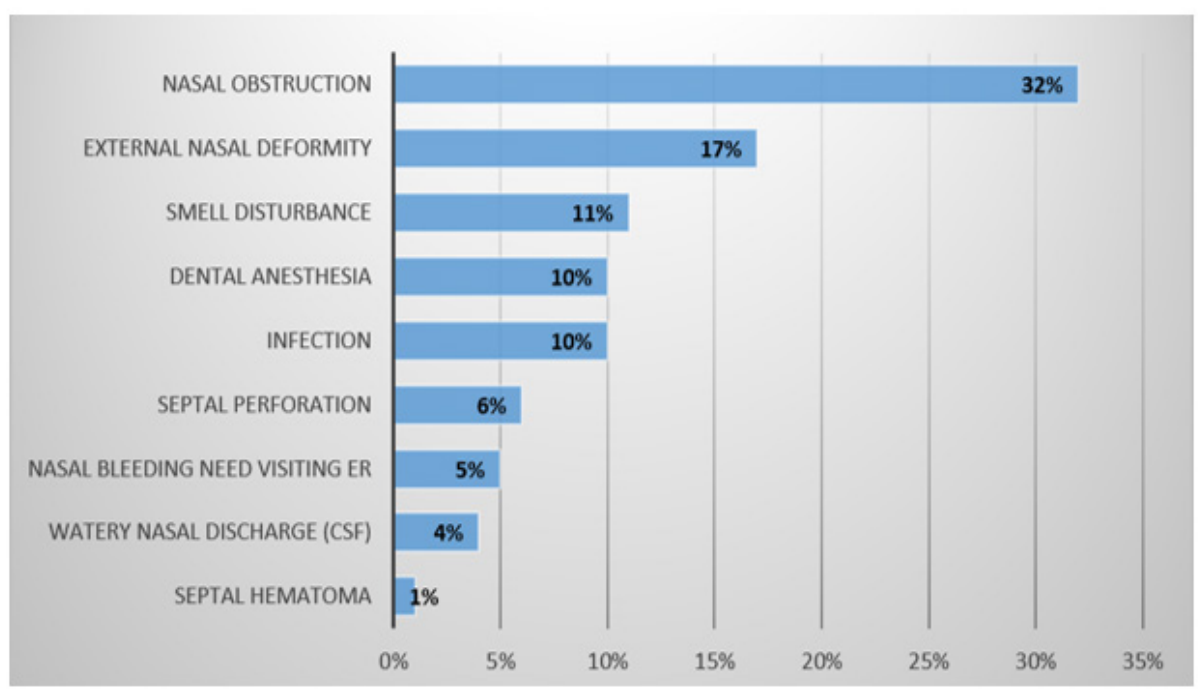

Figure 1: Postoperative complications among patients who have undergone septoplasty in Khamis Mushait General Hospital.

The study included a sample for a total number of 93 out of 120 cases. Sixty-five (69.9\%) of the patients aged less than 30 years and $60.2 \%$ were males (Table 1 ). As for postoperative complications, (Figure 1) demonstrates that $32 \%$ of the cases had nasal obstruction followed by external nasal deformity $(17 \%)$, may extend to the upper jaw and the tip of the nose. This almost always resolves within several months. The current study aimed to reveal the incidence of postoperative complications among patients with DNS and their relation to patients' age and gender.

\section{Methodology}

A retrospective Electronic data-based study was conducted including all patients with clinically diagnosed DNS and underwent surgical intervention (septoplasty) at Khamis Mushait General Hospital during the period from January 2017 to the end of May 2019. Patients excluded from the study were those with incomplete records or chose not to share their electronic data or could not be contacted via telephone. All electronic files were reviewed, and clinical data was recorded on a pre-form questionnaire. Data so collected included patients' demographics and postoperative complications for the surgery (Septoplasty) such as nasal obstruction, nasal deformity, smell disturbance, and all others.

\section{Data Analysis}

After data was analyzed using statistical software IBM SPSS (Statistical Package for the Social Sciences) version 22 All statistical analysis was done using two-tailed tests and an alpha error of 0.05. A P-value of 0.05 or less was considered statistically significant. The percentage was used to describe the frequency and the distribution of the different collected variables including patients' demographic data and postoperative complications. Cross tabulation was used to show the postoperative complications distribution in relation to patients' age and gender using exact probability tests. 
nasal deformity was recorded among $27 \%$ of the female patients compared to $10.7 \%$ of the male patients with recorded statistical significance $(\mathrm{P}=0.041)$ Septal perforation was recorded among $8.9 \%$ of the male cases compared to $2.7 \%$ of the females $(\mathrm{P}=0.232)$. Smell disturbance was recorded among $12.5 \%$ of the male patients compared to $8.1 \%$ of the female patients $(\mathrm{P}=0.503)$. Regarding the distribution of postoperative complications by patients' age, (Table 3) illustrates that nasal obstruction was recorded among $35.4 \%$ of the patients below the age of 30 years compared to $25 \%$ for those above 35 years $(\mathrm{P}=0.326)$. The external nasal deformity was reported in $21.5 \%$ of young patients ( $<30$ years) compared to
$7.1 \%$ of those who were older $(\mathrm{P}=0.05)$. Infections were observed among $10.8 \%$ of the young patients compared to $7.1 \%$ of older patients $(\mathrm{P}=0.587)$. CSF rhinorrhea was observed among $6.2 \%$ of the patients below 30 years compared to none of those who are older $(\mathrm{P}=0.180)$. (Table 4) demonstrates the relation between post-operative nasal deformity and patients' age and gender. Nasal deformity was recorded among $21.5 \%$ of cases below the age of 30 years compared to $7.1 \%$ of those above age of 30 years. Also, it was recorded for $27 \%$ of the female patients compared to $10.7 \%$ of the males with statistically significant difference $(\mathrm{P}=.041)$.

Table 1: Bio-demographic data of patients with DNS in Khamis Mushait General Hospital.

\begin{tabular}{|c|c|c|}
\hline Bio-demographic data & No. of patients & Percentage (\%) \\
\hline Age in years & & $69.9 \%$ \\
\hline$<30$ years & 65 & $30.1 \%$ \\
\hline$>30$ years & 28 & \\
\hline Gender & & $60.2 \%$ \\
\hline Male & 56 & $39.8 \%$ \\
\hline Female & 37 & \\
\hline
\end{tabular}

Table 2: Postoperative complications among patients who have undergone septoplasty according to their gender.

\begin{tabular}{|c|c|c|c|c|c|}
\hline \multirow{3}{*}{ Postoperative complications } & \multicolumn{5}{|c|}{ Gender } \\
\hline & \multicolumn{2}{|c|}{ Male } & \multicolumn{2}{|c|}{ Female } & \multirow[t]{2}{*}{ P-value } \\
\hline & No. & $\%$ & No. & $\%$ & \\
\hline Nasal obstruction & 17 & $30.4 \%$ & 13 & $35.1 \%$ & .629 \\
\hline Nasal bleeding needed visiting ER & 2 & $3.6 \%$ & 3 & $8.1 \%$ & .342 \\
\hline Septal perforation & 5 & $8.9 \%$ & 1 & $2.7 \%$ & .232 \\
\hline External nasal deformity & 6 & $10.7 \%$ & 10 & $27.0 \%$ & $.04^{*}$ \\
\hline Infection & 5 & $8.9 \%$ & 4 & $10.8 \%$ & .764 \\
\hline Smell disturbance & 7 & $12.5 \%$ & 3 & $8.1 \%$ & .503 \\
\hline CSF rhinorrhea & 2 & $3.6 \%$ & 2 & $5.4 \%$ & .67 \\
\hline Dental anesthesia & 5 & $8.9 \%$ & 4 & $10.8 \%$ & .764 \\
\hline Septal hematoma & 0 & $0.0 \%$ & 1 & $2.7 \%$ & .216 \\
\hline
\end{tabular}

P: Exact probability test, ${ }^{*} \mathrm{P}<0.05$ (significant)

Table 3: Postoperative complications among patients who have undergone septoplasty according to their age.

\begin{tabular}{|c|c|c|c|c|c|}
\hline \multirow{3}{*}{ Postoperative complications } & \multicolumn{5}{|c|}{ Age in years } \\
\hline & \multicolumn{2}{|c|}{$<30$ years } & \multicolumn{2}{|c|}{$>30$ years } & \multirow[t]{2}{*}{ P-value } \\
\hline & No. & $\%$ & No. & $\%$ & \\
\hline Nasal obstruction & 23 & $35.4 \%$ & 7 & $25.00 \%$ & .326 \\
\hline Nasal bleeding needed visiting ER & 3 & $4.6 \%$ & 2 & $7.10 \%$ & .620 \\
\hline Septal perforation & 4 & $6.2 \%$ & 2 & $7.10 \%$ & .859 \\
\hline External nasal deformity & 14 & $21.5 \%$ & 2 & $7.10 \%$ & $.050^{*}$ \\
\hline Infection & 7 & $10.8 \%$ & 2 & $7.10 \%$ & .587 \\
\hline Smell disturbance & 7 & $10.8 \%$ & 3 & $10.70 \%$ & .994 \\
\hline CSF rhinorrhea & 4 & $6.2 \%$ & 0 & $0.00 \%$ & .18 \\
\hline Dental anesthesia & 7 & $10.8 \%$ & 2 & $7.10 \%$ & .587 \\
\hline Septal hematoma & 1 & $1.5 \%$ & 0 & $0.00 \%$ & .509 \\
\hline
\end{tabular}

P: Exact probability test, ${ }^{*} \mathrm{P}<0.05$ (significant) 
Table 4: Distribution of post-operative nasal deformity according to patients' age and gender.

\begin{tabular}{|c|c|c|c|c|c|}
\hline \multirow{3}{*}{ Personal Data } & \multicolumn{5}{|c|}{ Post-Operative External Nasal Deformity } \\
\hline & \multicolumn{2}{|c|}{ No } & \multicolumn{2}{|c|}{ Yes } & \multirow[t]{2}{*}{ P-value } \\
\hline & No. & $\%$ & No. & $\%$ & \\
\hline \multicolumn{6}{|l|}{ Age in years } \\
\hline$<30$ years & 51 & $78.50 \%$ & 14 & $21.50 \%$ & \multirow{2}{*}{0.092} \\
\hline$>30$ years & 26 & $92.90 \%$ & 2 & $7.10 \%$ & \\
\hline \multicolumn{6}{|l|}{ Gender } \\
\hline Male & 50 & $89.30 \%$ & 6 & $10.70 \%$ & \multirow{2}{*}{$.041^{*}$} \\
\hline Female & 27 & $73.00 \%$ & 10 & $27.00 \%$ & \\
\hline
\end{tabular}

P: Pearson X2-test, ${ }^{*} \mathrm{P}<0.05$ (significant)

\section{Discussion}

The deviated nasal septum is a physical disorder of the nose, involving nasal septum displacement. Some displacement is common and is asymptomatic in $80 \%$ of patients [17]. Among $80 \%$ (31) people, the nasal septum is off-center or deviated narrowing one nasal passage [18]. A severely deviated nasal septum blocks one side of the nose and reduces airflow, causing breathing difficulty [19]. On diagnosis of a nasal septum deviation medical management using topical nasal steroids, antihistamines, and decongestants applied to the nasal mucosa is typically considered first-line management. In case of failure, surgical intervention (septoplasty) to correct the underlying septal deformity is the second line [20].

Besides nasal obstruction, the main indication for septoplasty is a markedly deviated nasal septum, which may be associated with epistaxis, sinusitis, obstructive sleep apnea, and headaches due to contact points within structures of the lateral nasal wall [21]. If the deviated nasal septum prevents access to the middle meatus to perform effective sinus surgery or endoscopic orbital procedures such as dacryocystorhinostomy or orbital decompression, or if trans-septal transsphenoidal hypophysectomy is pursued, septoplasty may be the preferred surgical intervention [22]. Septoplasty procedures may be associated with many postoperative complications [23]. Intraoperative bleeding and postoperative epistaxis are of particular concern in septoplasty given the high vascularity of the intranasal mucosa [24].

Postoperative local infection and septal abscess development ranges from $0.4 \%$ to $12.0 \%[25,26]$. Another complication including external nose deformity may be recorded. A significant improvement in the general appearance of the nose after septoplasty has been recorded between $0.4 \%$ to $3.4 \%$ [27].

The most commonly recorded defects arising from septoplasty are saddle nose deformity and supra tip depression. The nose may also become deviated with a projected tip, the columella retracted, or the alar cartilage collapsed [28,29]. Postoperative follow up of the patients showed that $55 \%$ of patients underwent septoplasty relieved of nasal obstruction. Among the complications following surgery, the most common was flap tear, seen in $55 \%$ of the patients
[14]. In the current study, Nasal obstruction was the commonest recorded postoperative complication $30.4 \%$ of the male patients compared to $35.1 \%$ of the females. and $35.4 \%$ for patients $<30$ years compared to $25 \%$ for patient $>30$ years though has no statistically significant relation with gender and age. The only significant postoperative complication statistically is nasal deformity. It is more common among female (27\%) than male $(10.7 \%)$ and significant more among those patients younger than 30 (21.5\%) years-old than older (7.1\%) [30,31]. Other post-operative complications were found to be insignificant statistically in relation with both gender and age.

\section{Conclusion and Recommendations}

Our study revealed that the only significant post-operative complication in relation with both gender and age groups is a nasal deformity. Nasal obstruction is the most common postoperative complication recorded in general among male and female patients as well as in all age groups although it has no significant relation to both gender and age groups. Multi-center trials should be conducted to give more understanding and further explanation.

\section{Acknowledgement}

None.

\section{Conflict of Interest}

None.

\section{References}

1. Abhishek S, Kapadia B, Patil NG, Shubhangi G (2017) Anatomical Variations of Nose and Para-Nasal Sinuses; CT Scan Review in South Gujarat.

2. Rao N, Datta G, Singh G (2020) To Study the Role of Nasal Septal Deviation and Its Relation to Sinonasal Pathology. Indian Journal of Otolaryngology and Head \& Neck Surgery 29: 1-5.

3. Van Egmond MM, Rovers MM, Tillema AH, Heerbeek NV (2018) Septoplasty for nasal obstruction due to a deviated nasal septum in adults: a systematic review. Rhinology 56(3): 195-208.

4. Shoib SM, Viswanatha B (2016) Association between symptomatic deviated nasal septum and sinusitis: a prospective study. Res Otolaryngol 5(1): 1-8.

5. Johnson MD (2017) Management of pediatric nasal surgery (Rhinoplasty). Facial Plast Surg Clin North Am 25(2): 211-221. 
6. Getz AE, Hwang PH (2008) Endoscopic septoplasty. Current opinion in otolaryngology \& head and neck surgery 16(1): 26-31.

7. Zielnik Jurkiewicz B, Olszewska Sosińska O (2006) The nasal septum deformities in children and adolescents from Warsaw, Poland. International journal of pediatric otorhinolaryngology 70(4): 731-736.

8. Kumar L, Belaldavar BP, Bannur H (2017) Influence of Deviated Nasal Septum on Nasal Epithelium: An Analysis. Head Neck pathol 11(4): 501 505.

9. Most SP, Rudy SF (2017) Septoplasty: basic and advanced techniques. Facial Plast Surg Clin North Am 25(2): 161-169.

10. Jessen M, Ivarsson A, Malm L (1989) Nasal airway resistance and symptoms after functional septoplasty: comparison of findings at 9 months and 9 years. Clin Otolaryngol Allied Sci 14(3): 231-234.

11. Konstantinidis I, Triaridis S, Triaridis A, Karagiannidis K, Kontzoglou G (2005) Long term results following nasal septal surgery: focus on patients' satisfaction. Auris nasus larynx. 32(4): 369-374.

12. Pedersen L, Schiöler L, Holmberg K, Ahlström Emanuelsson C, Hellgren J (2018) Age and unplanned postoperative visits predict outcome after septoplasty: a national Swedish register study. Int J Otolaryngol 18 2379536.

13. Shrestha KK, Joshi RR, Rijal AS, Dhungana A, Maharjan S (2019) Assessment of septoplasty outcome using Nasal Obstruction Symptom Evaluation scale. Nepal Medical College Journal 21(2): 142-146.

14. Rambabu P, Rao SS, KSRC TL (2018) Comparative Study of Complications in Endoscopic Septoplasty Versus Conventional Septoplasty. J Evid Based Med Healthc 5(44): 3080-3090.

15. Valsamidis K, Printza A, Titelis K, Constantinidis J, Triaridis S (2019) Olfaction and quality of life in patients with nasal septal deviation treated with septoplasty. American journal of otolaryngology 40(5): 747-754.

16. Tsang CL, Nguyen T, Sivesind T, Cervin A (2018) Long-term patientrelated outcome measures of septoplasty: a systematic review. Eur Arch Otorhinolaryngol 275(5): 1039-1048.

17. Gray LP (1978) Deviated nasal septum incidence and etiology. Ann Otol Rhinol Laryngol Suppl 87(2): 3-20.
18. Bhattacharyya N (2010) Ambulatory sinus and nasal surgery in the United States: demographics and perioperative outcomes. Laryngoscope 120(3): 635-638.

19. Akoglu E, Karazincir S, Balci A, Okuyucu S, Sumbas H, et al. (2007) Evaluation of the turbinate hypertrophy by computed tomography in patients with deviated nasal septum. Otolaryngol Head Neck Surg 136(3): 380-384

20. Holt GR (1999) Biomechanics of nasal septal trauma. Otolaryngol Clin North Am 32(4): 615-619.

21. Pletcher S, Sindwani R, Metson R (2006) Endoscopic orbital and optic nerve decompression. Otolaryngol Clin North Am Oct 39(5): 943-958.

22. Woog JJ, Sindwani R (2006) Endoscopic dacryocystorhinostomy and conjunctivoda-cryocystorhinostomy. Otolaryngol Clin North Am Oct 39(5): 1001-1017.

23. Ketcham AS, Han JK (2010) Complications and management of septoplasty. Otolaryngol Clin North Am 43(4): 897-904.

24. Orlandi RR, Warrier S, Han JK (2010) Concentrated topical epinephrine is safe in endo-scopic sinus surgery. Am J Rhinol Allergy 24: 140-142.

25. Yanagisawa E, Ho SY (1998) Unintended middle turbinectomy during septoplasty. Ear Nose Throat J 77(5): 36826

26. Mäkitie A (2000) Postoperative infection following nasal septoplasty. Acta Oto-Laryngologica 120(543): 165-166.

27. Yeo NK, Jang YJ (2009) Rhinoplasty to correct nasal deformities in postseptoplasty patients. Am J Rhinol Allergy 23(5): 540-545.

28. Tasca I, Compadretti GC (2011) Nasal growth after pediatric septoplasty at long-term follow-up. Am J Rhinol Allergy 25(1): e7-12.

29. Lee JJ, Hong SD, Dhong HJ, Chung SK, Kim HY (2019) Risk factors for intraoperative saddle nose deformity in septoplasty patients. Eur Arch Otorhinolaryngol 276(7): 1981-1986.

30. Ozan Kuduban, Fatih Bingol, Ali Budak, Cuneyt Kucur (2015) The Reason of Dissatisfaction of Patient after Septoplasty. Eurasian J Med 47(3): 190-193

31. McKenzie M (2016) Manual of diseases of the nose and the throat, Churchill, London, 432: 1880 